\title{
Economic-based approach for predicting optimal water pipe renewal period based on risk and failure rate
}

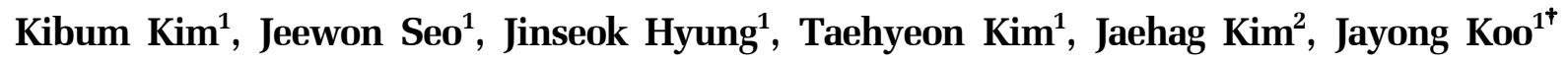 \\ ${ }^{1}$ Department of Environmental Engineering, University of Seoul, Seoul 02504, Republic of Korea \\ ${ }^{2}$ Metropolitan Water Supply Construction Office, K-water, Yongin 16935, Republic of Korea
}

\begin{abstract}
This study suggests a method for calculating the benefits of water pipe renewal based on an estimate of the water supply suspension risk. The proposed method based on five benefit items is more direct and specific than other benefit estimation methods. In addition, a methodology evaluating the economics of pipe renewal based on pipe failure rate is proposed for estimating the optimal renewal point from an economic perspective. By estimating the optimal renewal period based on a yearly benefit cost ratio per pipe in a case study area, it was possible to draft an optimal renewal plan for the subject region from an economic perspective. Compared with other methodologies, a reasonable optimal renewal period was derived from an economic point of view. The result of this study may be used to develop future water pipe renewal plans. Moreover, the proposed methodologies and results derived from this study can be applied to asset management plans.
\end{abstract}

Keywords: Economic evaluation, Optimal renewal period, Pipeline renewal, Water suspension

\section{Introduction}

Over time, underground water supply pipes which installed for efficiency and safety of water supply tend to deteriorate, due to various static, dynamic, and operational factors [1]. The static factors such as pipe diameter and soil characteristics are the conditions that do not change after the installation, the dynamic factors such as loadings and pipe age are the conditions that change after the installation. The operational factors such as water pressure and cathodic protection state that can be changed by the water pipe management method. Therefore, over a long period of time, all countries with buried water supply pipes will inevitably experience problems related to pipe deterioration. If an old deteriorated pipe is left as it is, the problems that can occur include poor water quality, increased friction/pressure loss, pipe breakage and leakage to mention a few. To solve these problems, it is necessary to replace, rehabilitate, or repair the aged pipe in a timely manner.

Table 1 shows the methodologies used by previous studies for estimating the pipe renewal period. These methodologies largely predict the pipe useful life from a physical point of view, which estimates the point at which the useful life is exhausted to the renewal/replacement point, and predicts the pipe breakage rate from a statistical point of view. The method estimates the renewal period as the point in time when the failure rate exceeds the critical failure rate, or the time that minimizes the life cycle cost.

If the cost of renewing the water supply pipe and the benefits resulting from the pipe renewal can be quantified as a monetary value, the renewal period can be calculated by analyzing the economic evaluation of the pipe renewal. Table 2 shows previous studies that used an economic perspective to determine the pipe renewal period based on a monetary benefit-cost analysis.

In particular, when a conveyance and transmission pipe is composed of a single line, the damage from a pipe failure can be considerably large. However, as the cost of renewing a large-diameter pipe is substantial, it is necessary to determine the appropriate renewal period. As can be seen from the presented studies, there are various ways to estimate the appropriate pipe renewal time. Among the various methods, the physical approach is based on an actual diagnosis of the pipe. Therefore, this can be considered the most accurate way to calculate the renewal point. However, if insufficient data are available for analysis,

Received November 21, 2017 Accepted May 30, 2018

${ }^{\dagger}$ Corresponding author

Email: jykoo@uos.ac.kr

Tel: +82-2-6490-2866 Fax: +82-2-5460-5465 
Table 1. Previous Studies on Finding the Renewal Period and Residual Life of Pipe

\begin{tabular}{|c|c|c|c|}
\hline & Method & Characteristics & Reference \\
\hline \multirow{5}{*}{$\begin{array}{l}\text { Physical/ } \\
\text { mechanistic } \\
\text { approach }\end{array}$} & $\begin{array}{l}\text { Prediction of remaining pipe thickness } \\
\text { and residual structural resistance }\end{array}$ & $\begin{array}{l}\text { A corrosion-depth prediction model was used to predict the residual } \\
\text { life of the pipe (Two-phase model). }\end{array}$ & {$[2,3]$} \\
\hline & Prediction of pipe safety factor & $\begin{array}{l}\text { The pipes useful life was determined using the SF (Safety Factor) } \\
\text { between the stress acting on the pipe and the residual strength. }\end{array}$ & {$[4,5]$} \\
\hline & Prediction of pipe corrosion rate & $\begin{array}{l}\text { A corrosion-depth prediction model was used to predict the residual } \\
\text { life of the pipe (Non-linear regression model). }\end{array}$ & {$[6]$} \\
\hline & Prediction of pipe corrosion & $\begin{array}{l}\text { The useful life expectancy of the pipe was predicted by a risk } \\
\text { assessment based on the corrosion depth prediction. }\end{array}$ & {$[7]$} \\
\hline & Prediction of pipe safety factor & $\begin{array}{l}\text { The useful life of the pipe was determined using the FoS (Factor } \\
\text { of Safety) between the stress (hoop stress, axial stress) and the residual } \\
\text { strength. }\end{array}$ & {$[8]$} \\
\hline \multirow{6}{*}{$\begin{array}{l}\text { Statistical/ } \\
\text { empirical } \\
\text { approach }\end{array}$} & Prediction of breakage frequency & $\begin{array}{l}\text { A time exponential breakage frequency prediction model was used } \\
\text { to determine the optimal replacement period. }\end{array}$ & {$[9,10]$} \\
\hline & Survival analysis by pipe failure & $\begin{array}{l}\text { The useful life of the pipe was determined using the survival rate } \\
\text { based on the Herz probability distribution. }\end{array}$ & {$[11,12]$} \\
\hline & $\begin{array}{l}\text { Genetic algorithm for minimizing the life } \\
\text { cycle cost }\end{array}$ & $\begin{array}{l}\text { An optimal renewal period was found that minimized the expected } \\
\text { renewal and damage costs using a genetic algorithm. }\end{array}$ & [13-15] \\
\hline & $\begin{array}{l}\text { Dynamic programming for minimizing } \\
\text { life cycle cost }\end{array}$ & $\begin{array}{l}\text { An optimal renewal period was found that minimized the expected } \\
\text { renewal and damage costs using a dynamic programming }\end{array}$ & {$[16]$} \\
\hline & Prediction of breakage frequency & $\begin{array}{l}\text { The threshold breakage rake was found by using a time } \\
\text { exponential-linear breakage frequency prediction model. }\end{array}$ & {$[17]$} \\
\hline & Prediction of breakage frequency & $\begin{array}{l}\text { The optimal replacement period was found by using a } \\
\text { non-homogeneous Poisson process for predicting the pipe breakage } \\
\text { frequency. }\end{array}$ & [18] \\
\hline
\end{tabular}

Table 2. Previous Studies for Finding the Renewal Period from an Economic Perspective

\begin{tabular}{ll}
\multicolumn{1}{c}{ Method } & \multicolumn{1}{c}{ Characteristics } \\
\hline $\begin{array}{l}\text { Calculation of benefit-cost ratio } \\
\text { Calculation of the allowable failure from }\end{array}$ & $\begin{array}{l}\text { The authors suggested that it is economically feasible to replace } \\
\text { a pipe when the benefit-cost ratio exceeds a predetermined level. }\end{array}$ \\
\hline $\begin{array}{l}\text { Benefit- } \\
\text { allowable failures, followed by replacing the pipe, if the pipe exceeded } \\
\text { the number of allowable failures. }\end{array}$ \\
[20]
\end{tabular}

distorted analysis results may be derived. Consequently, it is appropriate to use statistical and economical approaches when insufficient data for analysis are available.

In order to understand the economic feasibility of renewing a pipe, a methodology is needed to quantitatively estimate the benefits that would result from the renewal. Gaewski and Blaha [21] and Liu et al. [22] methodologies for quantifying the renewal benefits are suggested. However, they only present benefit items that are generated according to the renewal; no specific method is given for calculating the benefits. In addition, as in the case of Kim et al. [23], the benefits derived from a consumer's willingness to pay are typically based on survey results. Unfortunately, these results can be affected by the period and region in which the survey was conducted. Consequently, water pipes located in relatively poorer regions may increase the benefit-cost ratio, thereby making the pipe renewal benefits seem uneconomic.

The benefits generated by renewing a pipe can be said to be the same as the damage that occurs when the pipe is not renewed. In addition, the benefits generated through the renewal can be defined by quantifying the effect of the renewal on the monetary value.

Here, the risk of pipe failure can be estimated by multiplying the failure frequency by the damage caused by the failure. The monetary value of the risk can be used to quantify the damage caused by the pipe failure. 
Comprehensively, the purpose of this study is to develop a specific method for estimating the benefits of pipe renewal and to determine the renewal timing from an economic point of view. The objectives of this study are summarized as follows:

1) Develop a risk-based direct benefit measurement model for renewing pipes.

2) Develop a model for deriving the optimum pipe renewal point through annual economic evaluations.

3) Conduct a case study using the developed model.

\section{Methodology}

The method proposed in this study is shown in Fig. 1. After calculating the benefits and costs, respectively, an economic analysis was performed. Here, a substitution cost method based on the water suspension risk, which can be considered a direct method, was used to calculate the renewal benefits. The renewal costs were calculated by considering the unit cost of the renewal. The next step was to conduct a yearly economic evaluation; finally, an optimal renewal period was estimated.

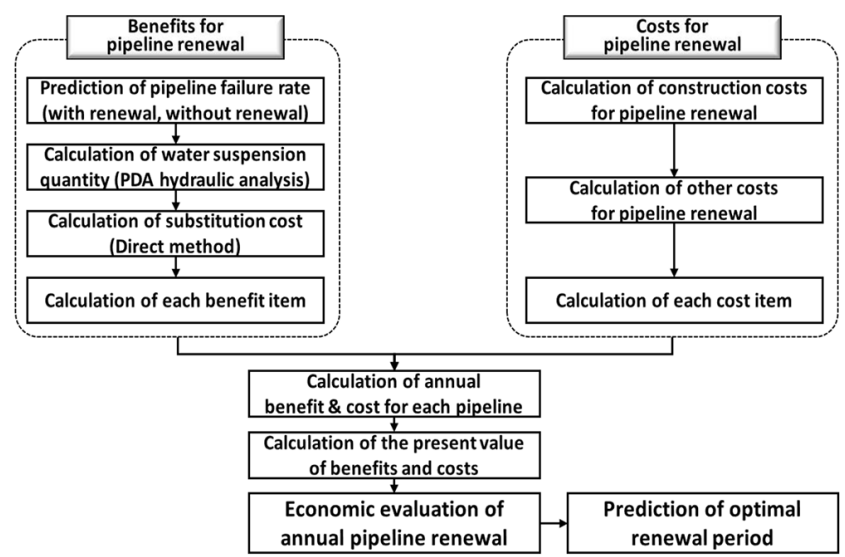

Fig. 1. Method proposed in this study.

\subsection{Benefits of Pipeline Renewal}

Damage, including pipe failure, can occur when deteriorated water pipes are not renewed; this means that renewing pipes can reduce the amount of damage that would otherwise occur. In this study, the expected damage from a single case of pipe failure was calculated, and the benefits of renewal were derived by estimating the number of failures that would be prevented by renewing the pipes.

There are various benefits for renewing a deteriorated pipe, such as reducing the repair cost, reducing the suspension damage cost, reducing the energy needed to run the pump station, reducing the legal and labor costs, increasing the water quality, and increasing the credibility of water service providers [21-23].

The benefits that result from renewing water pipes vary considerably. This study selects the following five specific areas of benefits that can be converted to monetary values to be quantitatively examined and evaluated using a direct methodology. Here's a limitation of this study. First, Because of data limitations, this study didn't consider the benefits associated with energy reduction.
However, an energy reduction cost due to the pipe renewal is clearly generated. Second, too much friction/pressure loss can cause a pipe to be replaced, and increasing or decreasing water demands can also require replacing a pipe with one of the appropriate diameter. This study did not consider these issues, research related to these issues is necessary to specify the benefit more.

Each item was calculated according to the respective formula presented as follows:

- Benefit from a reduction of the repair cost for a pipe failure (BRR)

$$
B R R=\left(F R_{W O}-F R_{W I}\right) \times L \times R C
$$

- Benefit from avoiding the damage cost of a living water suspension (BDL)

$$
B D L=\left(F R_{W O}-F R_{W I}\right) \times L \times P S \times t_{s} \times S C
$$

- Benefit from avoiding the damage cost by of a commercial water suspension (BDC)

$$
\begin{aligned}
B D C= & \left(F R_{W O}-F R_{W I}\right) \times L \times P S \times t_{s} \\
& \times W U_{c} \times\left(D C+W C_{t}\right)
\end{aligned}
$$

- Benefit from avoiding the damage cost by of an industrial water suspension (BDI)

$$
B D I=\left(F R_{W O}-F R_{W I}\right) \times L \times S Q \times V M P
$$

- Benefit from a reduction in social cost (BRS) _ if the pipe is buried under a road

$$
B R S=\left(F R_{W O}-F R_{W I}\right) \times L \times t_{r r} \times T J C
$$

Replacing a deteriorated pipe with a new one will result in a relatively low probability of failure. This will also reduce the cost of repairing a failure. BRR is considered a benefit in reducing the failure repair cost.

If the probability of failure is reduced, the number of water suspensions due to pipe failure also decreases. BDL, BDC, and BDI show the benefits of lowering the number of living, commercial, and industrial water suspensions, respectively. To calculate the benefit for a BDL, the number of failures that could be reduced was multiplied by the number of people affected by the suspension, the suspension hours, and the substitution cost. Here, the substitution cost is derived from the cost of replacing food and beverage water and washing water for the suspension time. In the BDC case, the cost of adding purified water to the reservoir and store was defined as the substitution cost. In the BDI case, the marginal production value of the industrial water was defined as the substitution cost, and the benefits were calculated.

The social benefit was calculated as the traffic-jam reduction benefit. Vehicles that pass along the road during a failure will have a reduced movement speed. The benefit is calculated by the cost of damage caused by the traffic congestion, as calculated in the report shown in Table 3 [27]. 
Table 3. Substitution Costs for Calculating the Benefit

\begin{tabular}{lll}
\hline \multicolumn{1}{c}{ Detailed cost item } & \multicolumn{1}{c}{ Applied value } & \multicolumn{1}{c}{ Reference } \\
\hline $\mathrm{RC}$ & $\begin{array}{l}\text { Applied differently according to the pipe diameter } \\
\text { (Table 4) }\end{array}$ & $\begin{array}{l}\text { MOLIT (Korea Ministry of Land, Infrastructure and } \\
\text { Transport) [24] }\end{array}$ \\
$\mathrm{PS}, \mathrm{t}_{\mathrm{s}}, \mathrm{WU}_{\mathrm{c}}, \mathrm{SQ}$ & Used the hydraulic analysis results \\
$\mathrm{SC}$ & $74,475 \mathrm{KRW}$ & MOLIT (Korea Ministry of Land, Infrastructure and \\
$\mathrm{DC}$ & $12,200 \mathrm{KRW}$ & Transport) [24] \\
$\mathrm{WC}_{\mathrm{t}}$ & $1,216 \mathrm{KRW}$ & MOLIT [24] \\
$\mathrm{VMP}$ & $9,948 \mathrm{KRW} / \mathrm{m}^{3}$ & MOE (Korea Ministry of Environment) [25] \\
$\mathrm{TJC}$ & $234,000 \mathrm{KRW} / \mathrm{h}$ & KDI (Korea Development Institute) [26] \\
\hline
\end{tabular}

* The Korea Republic Won (KRW) is the currency unit of South Korea. One United States Dollar (USD) is equivalent to 1,075 KRW (27 March 2018).

Table 4. Standard Repair Cost

\begin{tabular}{lccccc}
\hline Diameter (mm) & Road (1,000 KRW) & Other $\mathbf{( 1 , 0 0 0}$ KRW) & Diameter (mm) & Road (1,000 KRW) & Other (1,000 KRW) \\
\hline Below 300 & 12,149 & 5,685 & 600 & 19,467 & 11,413 \\
300 & 12,952 & 6,270 & 700 & 22,081 & 13,571 \\
400 & 15,098 & 7,957 & 800 & 25,341 & 16,342 \\
500 & 17,205 & 9,610 & 900 & 28,600 & 22,113 \\
\hline
\end{tabular}

To calculate and predict the benefit, as shown in Eq. (1) to (5), the pipeline failure rate needs to be predicted. As described in Eq. (6), the future failure rate was predicted, based on the failure function of the Cohort Survival Model [11]. This failure rate model utilizes statistical methodologies to estimate future pipe conditions over predetermined amounts of time, based on an analysis of the pipe's current condition [12]. To build a standardized model of a pipe's failure history, the failure history of the national multi-regional water supply of the Republic of Korea (Korea) during 1980-2015 was used [28]. The coefficient of the model function was derived by non-linear regression analysis performed using the SPSS statistics software version 24.0 (IBM Corporation).

$$
F R_{i}=\frac{b_{i} \cdot e^{b_{i}\left(t-c_{i}\right)}}{a_{i}+e^{b_{i}\left(t-c_{i}\right)}}
$$

The water suspension time $\left(\mathrm{t}_{\mathrm{s}}\right)$, the number of people who experience suspension (PS) in Eq. (2) and Eq. (3), the amount of commercial water usage $\left(\mathrm{WU}_{\mathrm{c}}\right)$ in Eq. (3), and the water supply shortage (SQ) in Eq. (4) are calculated by hydraulic analysis. The hydraulic analysis for a pipeline network can be classified as either a demand-driven analysis (DDA) or a pressure-driven analysis (PDA). The PDA methodology simulates the nodal outflow considering the hydraulic pressure of each node. When conducting a PDA, the head and amount of available water supply would be obtained [29]. In this study, the population affected by a water supply suspension, and the period of time over which it occurred, was calculated using the PDA module of the WaterGEMS program. This calculation took into consideration the relationship between available the demand and the required demand, and the reservoir retention volume at the point of failure of each pipe. The power function introduced by Wagner et al. [30], described in Eq. (7), was used to conduct the PDA hydraulic analysis. The value of $n$ was generally set to 0.5 . The threshold pressure was set to the normal reservoir level when no failure has occurred.

$$
\begin{gathered}
\left.q_{j}^{a v i}=q_{j}^{r e q} \text { (if } H_{j}^{a v i} \geq H_{j}^{d e s}\right) \\
0<q_{j}^{a v i}=q_{j}^{r e q}\left(\frac{H_{j}^{a v i}-H_{j}^{m i n}}{H_{j}^{d e s}-H_{j}^{\min }}\right)^{1 / n}\left(\text { if } H_{j}^{m i n}<H_{j}^{a v i}<H_{j}^{d e s}\right. \text { ) } \\
q_{j}^{a v i}=0 \text { (if } H_{j}^{a v i} \leq H_{j}^{\min } \text { ) }
\end{gathered}
$$

\subsection{Cost for Pipeline Renewal}

Kim et al.'s methodology [23] was used to calculate the renewal cost. The costs were divided into construction costs, which can be further divided into construction costs, incidental expenses, and land acquisition costs, and other extra costs. The investigation cost $(1.0 \%$ of the construction cost), design cost $(1.0 \%$ of the construction cost), and management cost (5.0\% of the construction cost) are composed of incidental expenses.

This study considered the fact that the water supply might not be sufficient for the time required to renew a large-diameter pipe composed of a single line. It is assumed that a dual-line pipe corresponding to $70 \%$ of the supply quantity, which can deliver the daily average quantity, was also installed together when renew the pipe.

The basic per-unit construction cost was set according to the pipe diameter and pipe material, as this is the most widely used approach in Korea. To consider price increases over time, an in- 
flation rate of $2.0 \%$ was applied to the construction cost per pipe diameter. The duration of a pipe renewal is assumed to be one year.

\subsection{Annual Economic Evaluation for Pipeline Renewal}

Much like many previous analyses, an economic evaluation indicator was provided via the benefit-to-cost ratio (B/C) defined in Eq. (8). The time frame for analysis was $45 \mathrm{y}$, with a social discount rate of $5.5 \%$ being applied during the first $30 \mathrm{y}$; the social discount rate was reduced to $4.5 \%$ for the remaining 15 y. The benefits were calculated as a cost per failure basis. Thus, although the accumulated benefit, i.e., monetary cost reduction, of performing pipe renewal at each point of failure differed according to the point of analysis, the benefit of preventing a pipe failure did not vary, because the monetary cost was a fixed at a flat price for each year. All remaining factors used in the benefit-cost function were set as described in previous studies [23].

$$
B / C=\sum_{t=1}^{n} \frac{B_{t}}{(1+r)^{t}} / \sum_{t=1}^{n} \frac{C_{t}}{(1+r)^{t}}
$$

\section{Results of Case Study}

\subsection{Failure Rate Prediction Model}

In this study, the failure rate prediction model was developed for steel pipe (SP) and ductile cast iron pipe (DCIP) where data can be obtained. The proposed method can be applied to other pipe materials also, when the actual failure histories are obtained.

The failure rate was estimated in advance, as shown in Fig. 2 and Fig. 3, to calculate the total benefit of the pipe renewal. The failure rate for DCIP was calculated as 0.3354 failures $/ \mathrm{km} / \mathrm{y}$, which is lower than that for SP (0.4852 failures $/ \mathrm{km} / \mathrm{y})$. The correlation coefficient of the SP model was 0.9193, DCIP model was 0.8704 which means the model is statistically significant.

This result was based on an investigation of failures occurring over a certain length of pipe. More specifically, the failure rate results were calculated using data from historical failures that

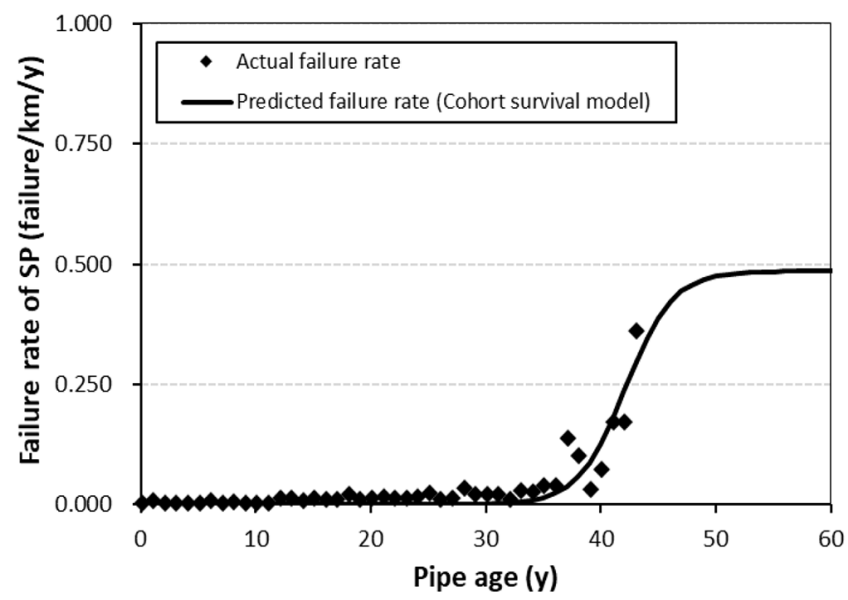

Fig. 2. Failure rate prediction model for SP.

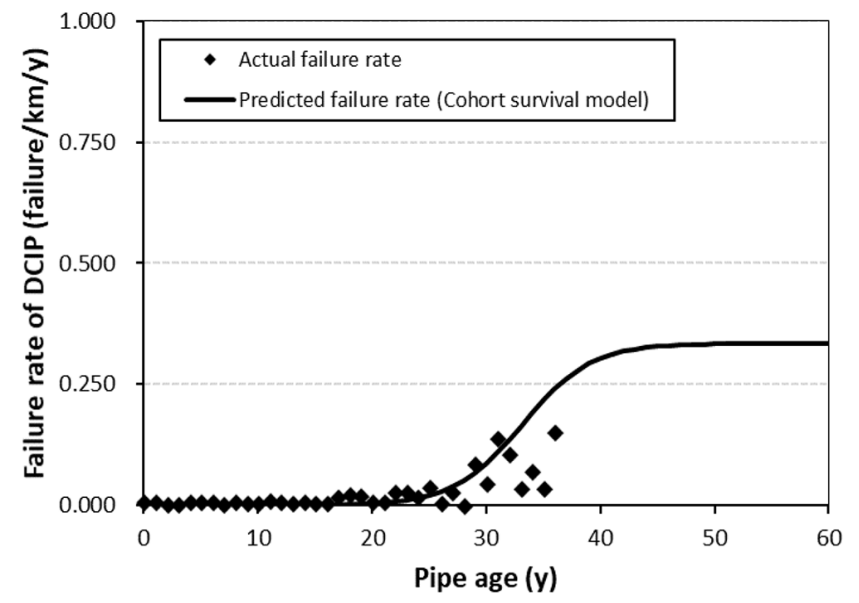

Fig. 3. Failure rate prediction model for DCIP.

raised concerns over a potential suspension of the water supply. As SP tends to be used more often than DCIP in Korea for larger diameter pipes, a water supply suspension caused by their failure would have a greater impact on the corresponding region. Considering this, the history of DCIP failures in this region has shown that few failures were not sufficiently large to threaten a water supply suspension. This is assumed to be the reason why the DCIP failure rate was found to be lower than that for SP.

In summary, the analysis results at the present time show that the failure rate of DCIP is lower than that of SP; however, results of analysis based on new data accumulated in the future may lead to different results from the analysis results at present.

\subsection{Description of Case Study Area and PDA Analysis}

The subject of this case study is the " $K$ " multi-regional water supply system depicted in Fig. 4. The multi-regional water supply in Region K supplies $68,732 \mathrm{~m}^{3} / \mathrm{d}$ of purified tap water to K City, an industrial city with about 250,000 residents in 2015. K City has two national industrial complexes related to the shipbuilding industry, depicted as S industry and D industry in Fig. 4. The SD2, and DM water supply areas are mainly residential areas and the IW water supply area is a concentration of tourist complexes. The YJ, SW water supply areas are densely packed shopping district areas. The other water supply areas cover the small-scale factories.

Since the city specializes in shipbuilding and other industries related to the steel industry, many residents are concerned about that the transmission pipe consists of a single-line. The multi-regional water supply pipe of Region $\mathrm{K}$ was installed over 30 years ago and has experienced 32 failures over its period in use. The total pipe length is $69.967 \mathrm{~km}$.

According to the law in Korea, a large-diameter water supply pipe should be regularly diagnosed for safety once every five years. The diagnostic results are expressed in five grades, as shown in Table 5. A safety diagnosis was conducted on the multi-regional water supply pipe of Region $\mathrm{K}$ in 2010 . The result showed a Grade $\mathrm{C}$ for the pipes, indicating that they require replacement. As a result, measures have been taken to increase the amount of emergency storage in the industrial area. However, the fundamental solution, renewing the pipe, has not been done. 


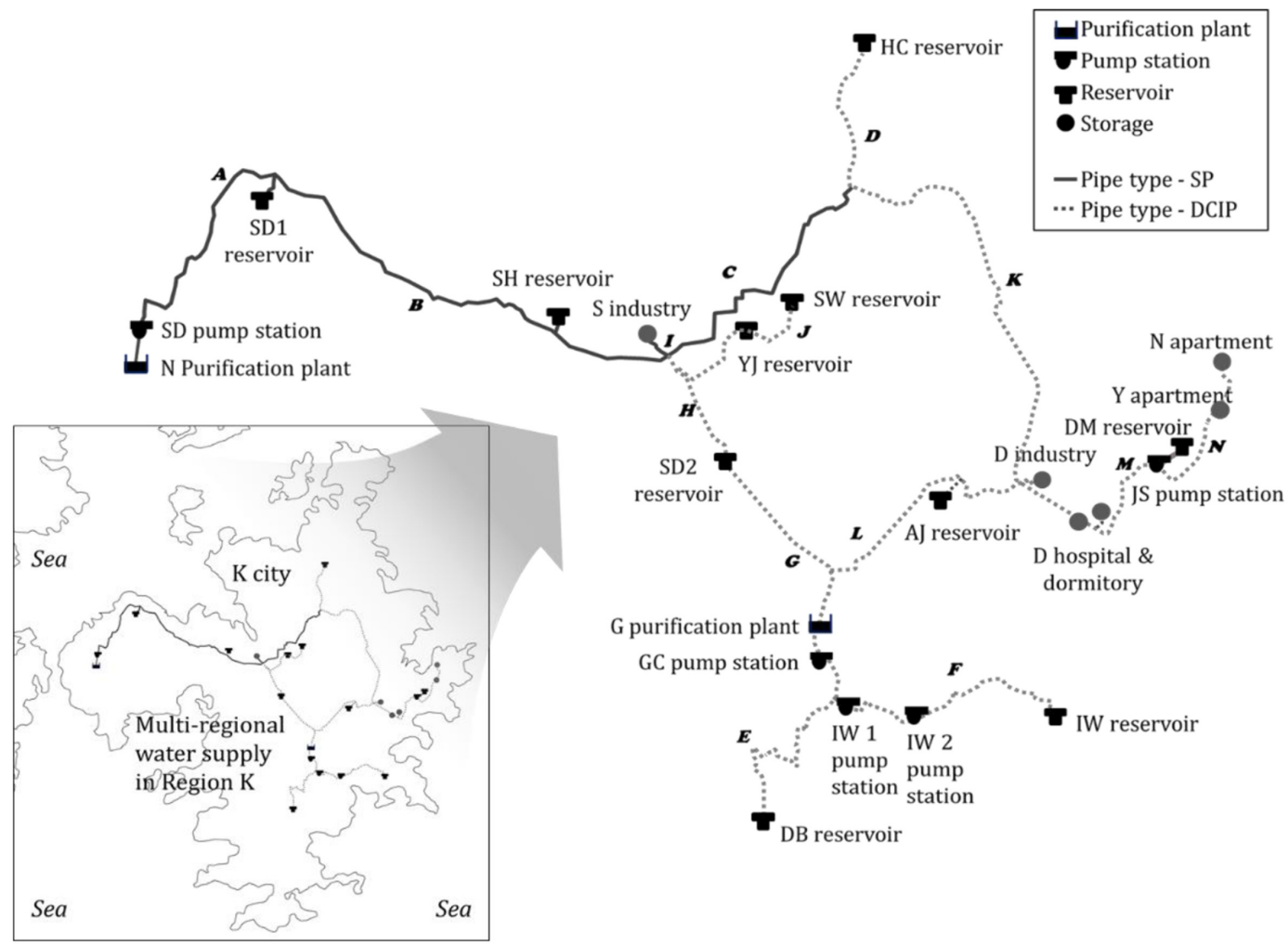

Fig. 4. Case study area (K multi-regional water supply).

Table 5. Grades for Diagnostic Results in Korea

\begin{tabular}{cl} 
Grade & \multicolumn{1}{c}{ Pipe condition and safety measures } \\
A & No defects appeared. The possibility of durability degradation is low. \\
B & $\begin{array}{l}\text { Some parts showed minor detects. The possibility of degradation and the performance level should be examined continuously, } \\
\text { considering the external environmental conditions. }\end{array}$ \\
C & $\begin{array}{l}\text { A wide range of parts were examined for minor defects. The safety performance of the entire pipe is not affected, and } \\
\text { there is no inconvenience. However, the possibility of degradation and the performance level should be examined } \\
\text { continuously, as some parts may require reinforcement, repair, rehabilitation or replacement. }\end{array}$ \\
D & The performance level requires urgent renewal and might not be safe to use. \\
E & $\begin{array}{l}\text { Serious defects were found in a wide range of parts and the safety performance level will soon be threatened. Use } \\
\text { should be discontinued immediately. }\end{array}$
\end{tabular}

Fig. 5 depicts the region that experiences water failure when Pipe A2 fails, and provides an estimate of the amount of damage. The results show that the SD1, SH, and SD2 supply areas are predicted to be severely affected by a suspension. The remaining supply areas are not predicted to experience any damage because of auxiliary services by a $\mathrm{G}$ purification plant and/or a reservoir. In addition, the total damage cost resulting from the Pipe A2 failure is estimated at $384,713,000 \mathrm{KRW}$ (approximately \$380,000).

\subsection{Results of Benefit and Cost Determination in Case Study Area}

As shown in Fig. 5, the benefits of renewing the other individual pipes were calculated. Based on the amount of suspended water, the cost of a single failure per major pipe (A2, B2, D2, M2), as determined by PDA, is presented in Table 6 . Note that the failures of Pipes A2 and B2, located in the upper area of the supply pipe would result in a wider ranging suspension of the water supply; this implies an increased cost. However, water passing through Pipes A2 and B2 partially supplies industrial areas, which have a relatively high average water retention volume. Consequently, although a water supply suspension in industrial areas can result in moderate damage, suspension does not occur when Pipe A2 or B2 fails. Thus, the BDI was set as 0 .

Because the failure rate and the extent of damage resulting from a water supply suspension are dependent on the individual pipe location within the pipeline network, the benefit cost ratio differed for each pipe. Pipes A2 and B2 showed higher benefits 


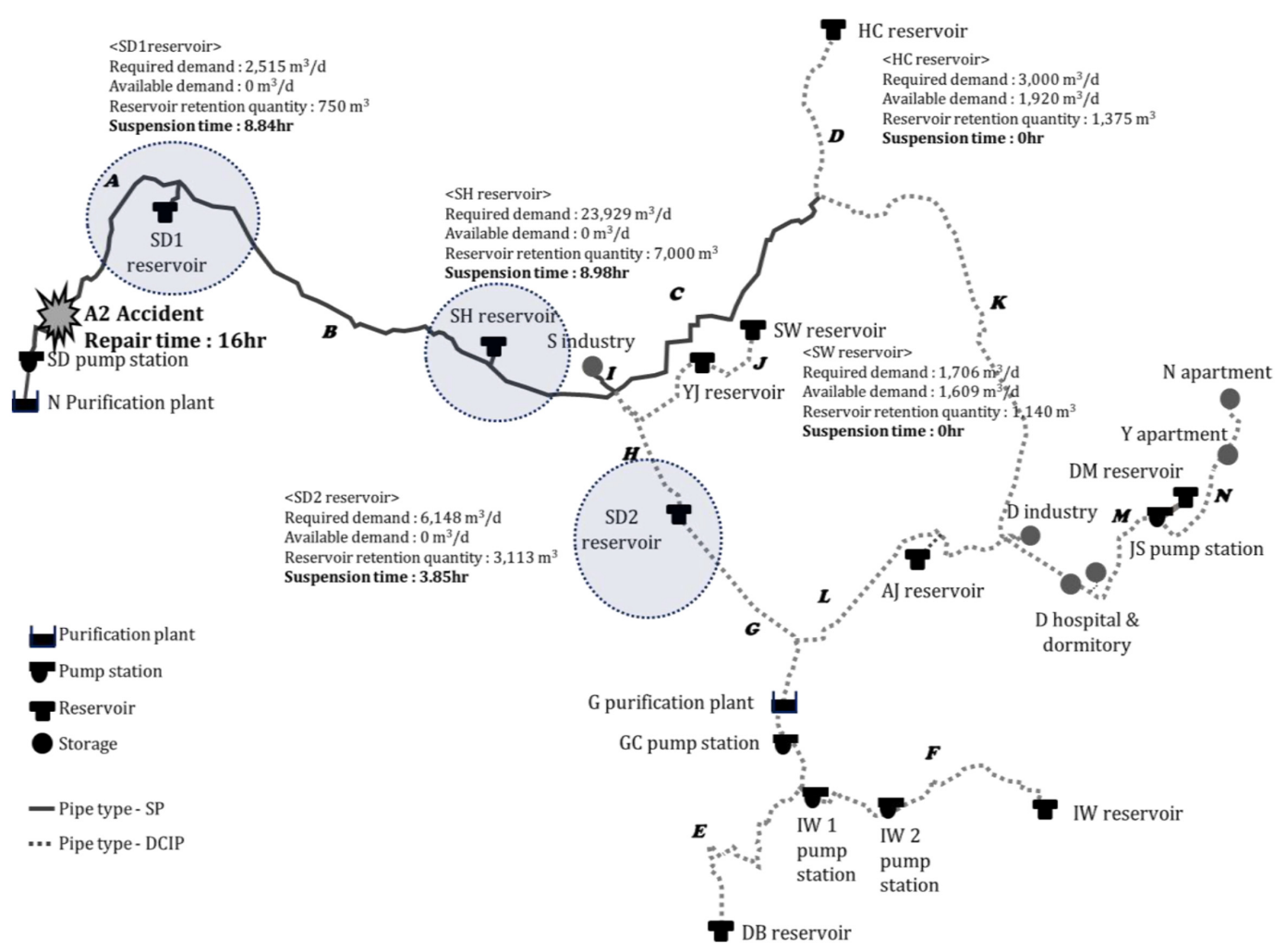

Fig. 5. Result of PDA (Example of A2 pipe failure).

Table 6. Damage Cost for One Failure (Examples of Pipe A2, B2, D2, M2)

\begin{tabular}{cccccccc}
\hline \multirow{2}{*}{ Pipe } & \multirow{2}{*}{ Pipe material } & \multicolumn{3}{c}{ Damage cost per one failure (1,000 KRW/1 failure) } & \multicolumn{2}{c}{ Total } \\
\cline { 3 - 7 } & & BRR & BDL & BDC & BDI & BRS & $(\mathbf{1 , 0 0 0}$ KRW / 1 failure) \\
\hline A2 & SP & 28,600 & 261,455 & 85,886 & 0 & 8,772 & 384,713 \\
\hline B2 & SP & 28,600 & 239,163 & 79,858 & 0 & 8,772 & 356,393 \\
\hline D2 & DCIP & 8,794 & 15,035 & 7,188 & 0 & 0 & 31,017 \\
\hline M2 & DCIP & 8,794 & 30,696 & 23,150 & 0 & 0 & 62,640 \\
\hline
\end{tabular}

than pipes D2 and M2. The D2 and M2 pipes are located at the end of the network, relative to the A2 and B2 pipes; thus, their costs are small because the absolute amount of suspension damage due to a water supply suspension is small.

Fig. 6 and Fig. 7 show the total benefit and cost, respectively. Fig. 6 shows that the benefits of renewing Pipes A2 and B2 cease to increase after a certain period of time. Conversely, the costs associated with these pipes continue to increase over time as a result of inflation, as shown in Fig. 7. In terms of the benefit cost ratio for Pipes A2 and B2, as can be seen in Fig. 8, this ratio initially increases before reaching a peak and decreasing as the renewal period is delayed.

Shamir and Howard [9], Shin et al [15], and Park and Loganathan [17] have used predictions that show infinite increases in future failure rates. The point at which the resulting benefits are greater than the cost is called the appropriate renewal period from an economic point of view. However, since this study utilizes the prediction result in which the future failure rate converges to

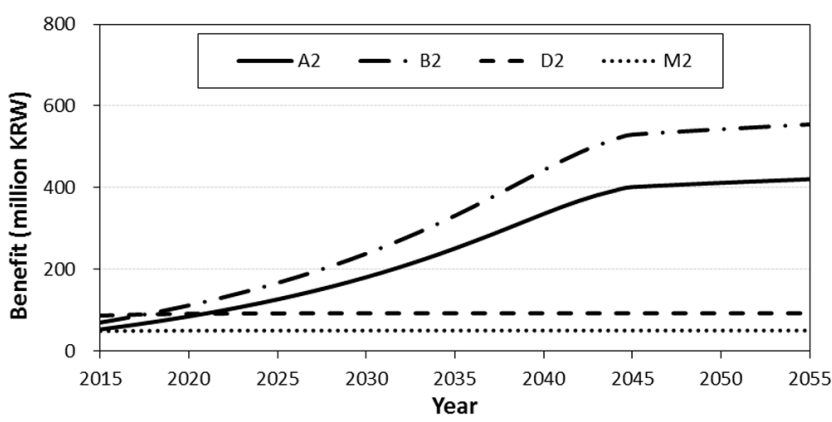

Fig. 6. Annual forecasting of benefit results (Examples of Pipe A2, B2, D2, M2).

a certain value, the benefit increase converges from a certain point of time, while the cost increase continuously increased, and the benefit cost ratio is decreases after reaching the peak point. 


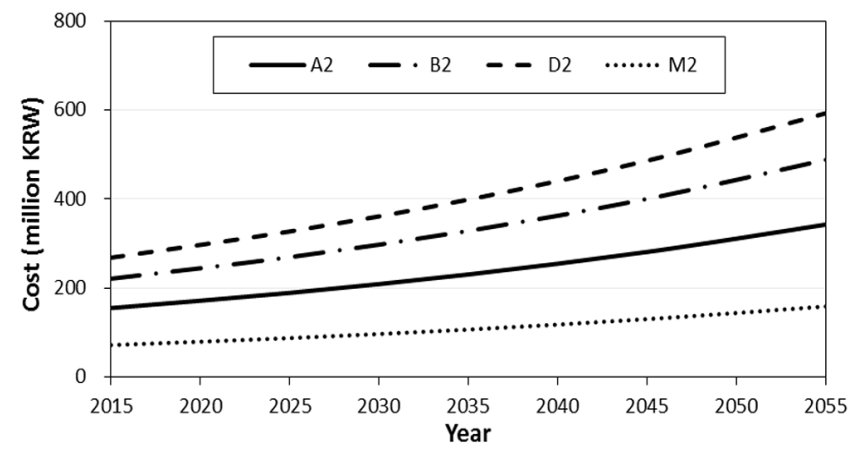

Fig. 7. Annual forecasting of cost results (Examples of Pipe A2, B2, D2, M2).

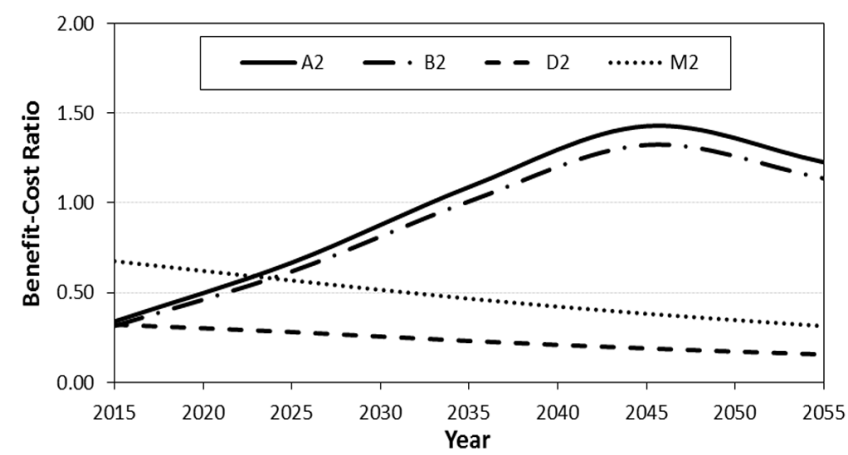

Fig. 8. Annual forecasting of benefit cost ratio results (Examples of Pipe A2, B2, D2, M2).

\subsection{Optimal Renewal Period of the Case Study Area}

This observation suggests that, from a purely economic perspective, it would be optimal to renew Pipe A2 in 2045, and Pipe B2 in 2046. In addition, in the case of $\mathrm{A} 2$, it is reasonable from an economic point of view to implement renewals after 2033, because at that point, the benefit cost ratio of renewing A2 is more than 1.0.

It should be noted that the decrease in the benefit cost ratio is because the failure rate estimation model used in this study shows the benefits associated with each pipe converging to some value after a certain period of time following the renewal.

Fig. 8 shows that there is no economically feasible period to renew Pipes D2 and M2. Therefore, their optimal renewal time can be determined based on their service life. In this study, the service life of SP and DCIP was set to $40 \mathrm{y}$. To consider the optimal renewal period, Fig. 9 illustrates the optimal time for pipe renewal and an economically feasible renewal period for the individual pipelines of the multi-regional water supply of Region K. The results obtained from yearly benefit cost analyses indicated that, from an economics perspective, Systems D, H, M, and N required immediate renewal to maintain a sustainable water supply.

The A2 pipe is located at the upper part of the water supply, therefore it can be said that the damage range due to the pipe failure is relatively larger than others. The A2 pipe was installed in 2001, and the optimum renewal period derived from the suggested method is 2045. At this time, the benefit cost ratio is 1.43.

In Korea, the service life of water pipe is set to $30 \mathrm{y}$ according to the law. If the A2 pipe is replaced in 2031, $30 \mathrm{y}$ after the

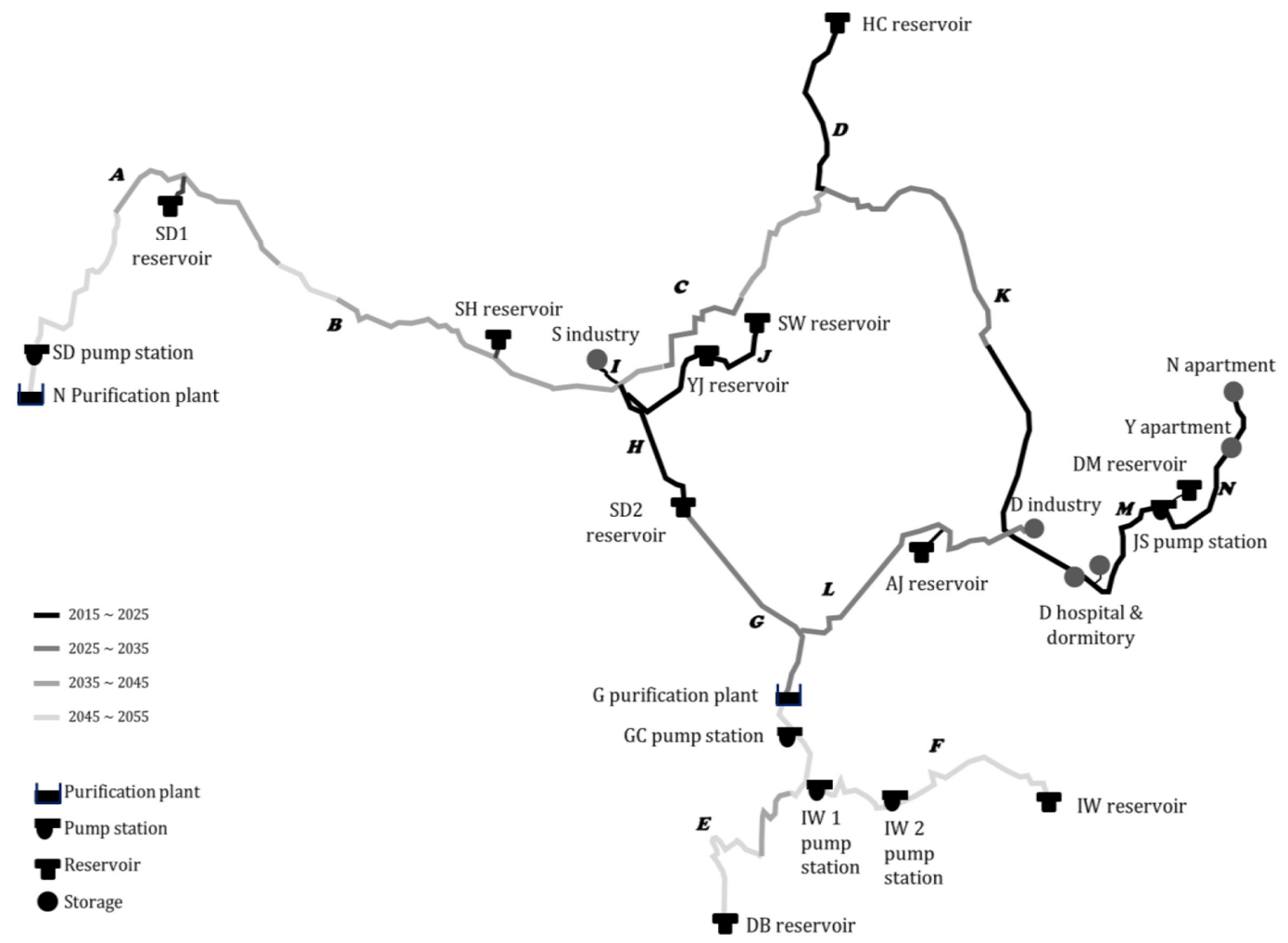

Fig. 9. Optimal time for renewal and economically feasible period (case study area). 
Table 7. Comparison of Results of Finding Renewal Period (Example of pipe A2)

\begin{tabular}{lcccc}
\hline \multicolumn{1}{c}{ Method } & $\begin{array}{c}\text { Optimal renewal } \\
\text { period }\end{array}$ & $\begin{array}{c}\text { Renewal cost in renewal period } \\
(\mathbf{1 , 0 0 0} \text { KRW) }\end{array}$ & $\begin{array}{c}\text { Total benefits after renewal from } \\
\text { renewal period (1,000 KRW) }\end{array}$ & $\begin{array}{c}\text { Benefit cost } \\
\text { ratio }\end{array}$ \\
\hline Using service life & 2031 & 193,371 & 212,994 & 0.91 \\
Using physical method & 2050 & 418,617 & 310,293 \\
Using proposed method & 2045 & 401,448 & 281,042 & 1.35 \\
\hline
\end{tabular}

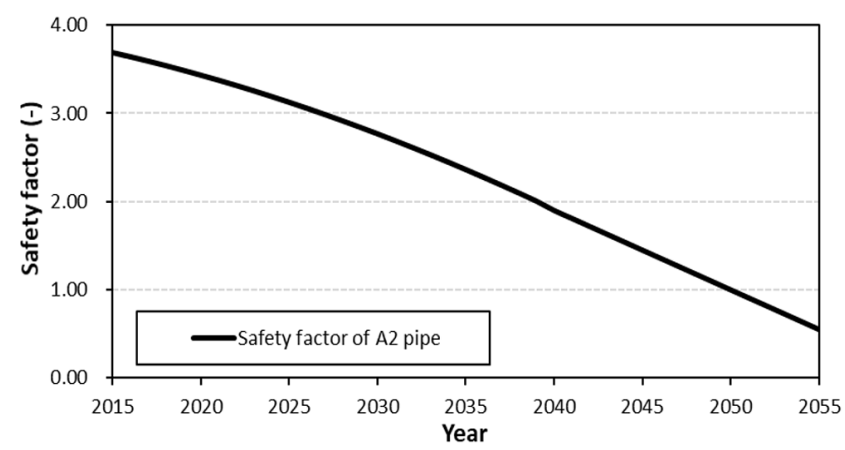

Fig. 10. Safety factor prediction of A2 pipe.

installation, the benefit cost ratio is 0.91 which is smaller than 1.0. That is, the cost of renewal is larger than the benefit.

The follwing is the prediction result of renewal period of A2 pipe using the safety factor proposed by Deb et al. [4]. Depending on the method by Deb et al. [4], which considering the stress acting on pipe and residual strength, Fig. 10 shows the change in safety factor of A2 pipe over time. Here, the stress was obtained based on the results of the safety diagnosis conducted in 2010. And the remaining strength of pipe was calculated using the relational equation between the corrosion rate of pipe and residual strength as shown in Eq. (9) proposed by Bae et al. [6]. The corrosion rate of pipe was calculated by the expected results of the corrosion depth by pipe age and pipe thichness. Kim [31] developed a corrosion depth prediction model using the results of the safety diagnosis of the large-diameter pipes in Korea. This study used a corrosion depth prediction model developed by Kim [31] as shown in Eq. (10).

$$
\begin{gathered}
\sigma_{\text {strength }}=d \times P_{c}+e \\
D_{S E}=0.0629 \cdot t+0.0050 \cdot\left(1-e^{-4.0962 \cdot t}\right)+0.001 \cdot f_{1}+0.005 \cdot f_{2}
\end{gathered}
$$

In general, if the safety factor is less than 1.0, then the proper renewal period of the A2 pipe is 2050. The benefit cost ratio for replacing the A2 pipe in 2050 is 1.35 .

Table 7 shows the result of finding renewal period by three methods (using service life, using physical method, using proposed method). From the economic perspective, the proposed method in this study showed the most reasonable results.

\subsection{Optimal Renewal Period of the Case Study Area under Water Demand Changes}

As described in Methodology, this case study did not consider changes in the water demand. However, as can be seen from Balogun et al.' study [32], an increase or decrease in the water demand may require a pipe renewal, irrespective of the economic efficiency. Changes in water demand should be considered when establishing a renewal plan.

The followings are the results of estimating the optimal renewal period when the water demand in the case study area from $80 \%$ to $120 \%$ of the current water demand. The current capacity of each reservoir is assumed to be unchanged. The results for the major pipe A2 and M2 are shown in Fig. 11 and Fig. 12.

As can be seen in Fig. 11, the optimal renewal period of water pipe was not related to the water demand changes. That is, the point at which the benefit cost ratio is maximum is fixed. This can be attributed to the convergence of the pipe failure prediction model used in this study.

However, the reasonable renewal period, the benefit cost ratio is larger than 1.0, was changed by water demand. If the amount of water demand is large, the damage range due to pipe failure is large. Therefore, as water demand increase, the benefit become larger. Since the size of the benefit changes in fixed costs, it can be understood that the appropriate renewal period also changes.

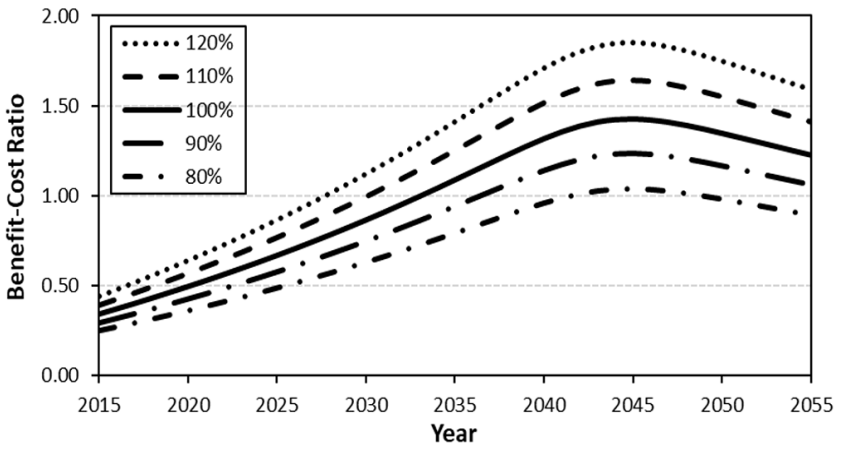

Fig. 11. Optimal renewal period of $\mathrm{A} 2$ pipe by water demand.

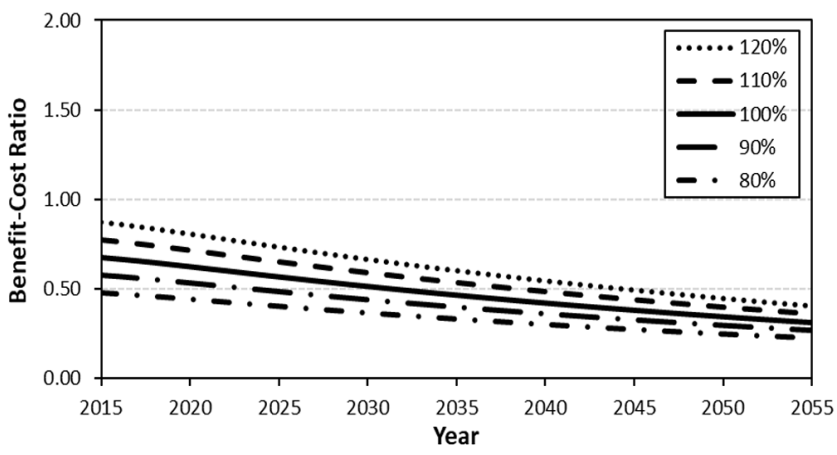

Fig. 12. Optimal renewal period of M2 pipe by water demand. 


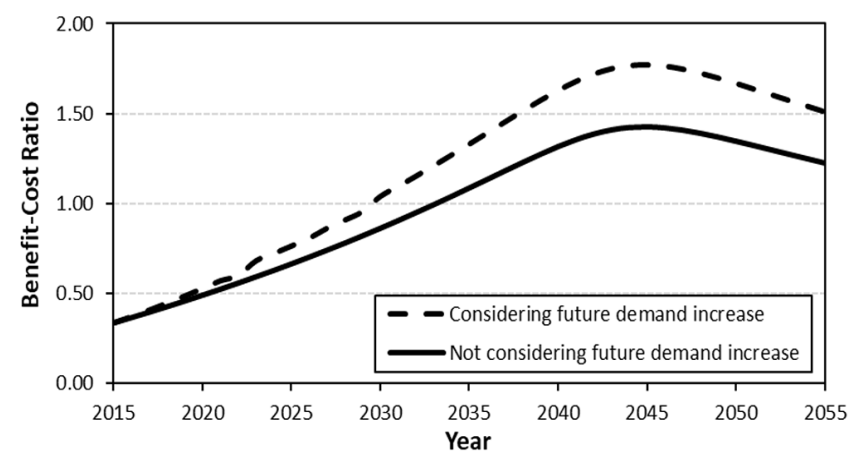

Fig. 13. Optimal renewal period of A2 pipe considering future demand increase by development project.

Fig. 13 compares increasing water demand according to an actual development plans in case study area and not considering the development plans. From 2020 to 2030, there will be 21 development projects in case study area and amount of 36,000 people will expected to increase. As shown in Fig. 11, the optimal renewal period of the A2 pipe is independent of water usage. However, the reasonable period to make renewal was advanced from 2033 to 2029.

\section{Conclusions}

In this study, to determine an optimal pipe renewal period from an economic perspective, a methodology for calculating the benefit of pipe renewal and an economic evaluation was suggested.

The key results and findings from this study were as follows:

1) Five risk-based benefit items for direct and specific benefit measurement model for renewing pipes were developed. The benefits of water pipe renewal were determined by estimating the failure rate of individual pipes, and then using the results to evaluate the risk of water supply suspension by a PDA. The proposed methodology was meaningful in that it embodied the benefits of pipe renewal.

2) Regarding the failure rate prediction, the correlation coefficient for the estimated and actual failure rates exceeded 0.85 ; this result indicates that the failure prediction model developed in this study yields results that are comparable to actual pipe failure trends.

3) A model for deriving the optimum pipe renewal point through an annual economic evaluation was developed to determine an optimal pipe renewal period. Applying the developed model to the case study area confirmed the applicability of the model.

By estimating the optimal renewal period based on a per-pipe yearly benefit cost ratio, it was possible to draft an economic-based optimal pipeline renewal plan for a particular region. Although the case study was conducted for the $\mathrm{K}$ region in Korea, it is believed that the methodology proposed in this study can be applied in all regions where the data used in this study can be obtained.

Meanwhile, this study has the limitations, as described in methodology related to data acquisition, additional research considered necessary for the relevant parts.

Finding the optimum renewal period of water pipes can be said to be the core of water pipes asset management. Consequently, the methodology and results from this study can be applied to supplement and complement the development and maintenance of an asset management plan for pipeline maintenance.

\section{Acknowledgments}

This work was supported by the 2017 Research Fund (20170425 1093) of the University of Seoul, Republic of Korea.

\section{Nomenclature}

$\mathrm{FR}_{\mathrm{WO}}$ pipeline failure rate without renewal (failure $/ \mathrm{km} / \mathrm{y}$ )

$\mathrm{FR}_{\mathrm{WI}}$ pipeline failure rate with renewal (failure $/ \mathrm{km} / \mathrm{y}$ )

$\mathrm{L}$ pipeline length $(\mathrm{km})$,

$\mathrm{RC}$ repair cost per pipeline failure (KRW/failure)

PS people who experienced suspension (people)

$\mathrm{t}_{\mathrm{s}} \quad$ water suspension time (h/failure)

SC substitution cost of living water per 1person (KRW/person/d)

$\mathrm{WU}_{\mathrm{c}}$ amount of commercial water use $\left(\mathrm{m}^{3} / \mathrm{d}\right)$

DC operation cost of water appendix vehicle $\left(\mathrm{KRW} / \mathrm{m}^{3} / \mathrm{fai}\right.$ lure)

$\mathrm{WC}_{\mathrm{t}} \quad$ cost of tap water $\left(\mathrm{KRW} / \mathrm{m}^{3}\right)$

SQ water supply shortage $\left(\mathrm{m}^{3} /\right.$ failure $)$

VMP value of marginal product $\left(\mathrm{KRW} / \mathrm{m}^{3}\right)$

$\mathrm{t}_{\mathrm{rr}} \quad$ repair time $(\mathrm{h})$

TJC cost of traffic jam (KRW/h/failure)

$\mathrm{FR}_{\mathrm{i}} \quad$ pipeline failure rate of pipe material i (failure $/ \mathrm{km} / \mathrm{y}$ ) ( $\mathrm{i}=1:$ SP, $\quad \mathrm{i}=2:$ DCIP)

$a_{i} \quad$ aging factor of pipe material i $\left(y^{-1}\right)$

$b_{i} \quad$ aging factor of pipe material $i\left(y^{-1}\right)$

$\mathrm{C}_{\mathrm{i}} \quad$ Retention time of pipe material i $(\mathrm{y})$

$\mathrm{t} \quad$ Pipe age (y)

$\mathrm{q}_{\mathrm{j}}{ }^{\text {avi }} \quad$ available demand at node $\mathrm{j}\left(\mathrm{m}^{3} / \mathrm{d}\right)$

$\mathrm{q}_{\mathrm{j}}^{\text {req }}$ required demand at node $\mathrm{j}\left(\mathrm{m}^{3} / \mathrm{d}\right)$

$\mathrm{H}_{\mathrm{j}}^{\mathrm{avi}}$ head at node $\mathrm{j}(\mathrm{m})$

$\mathrm{H}_{\mathrm{j}}^{\mathrm{min}}$ minimum head at node $\mathrm{j}(\mathrm{m})$

$\mathrm{H}_{\mathrm{j}}^{\mathrm{des}}$ threshold head at node $\mathrm{j}(\mathrm{m})$

$\mathrm{B}_{\mathrm{t}} \quad$ benefit at $\mathrm{t}$ year $(\mathrm{KRW} / \mathrm{y})$

$\mathrm{C}_{\mathrm{t}} \quad$ cost at $\mathrm{t}$ year $(\mathrm{KRW} / \mathrm{y})$

$\mathrm{r} \quad$ social discount rate (\%)

$\sigma_{\text {strength }}$ residual strength $\left(\mathrm{N} / \mathrm{m}^{2}\right)$

$\mathrm{P}_{\mathrm{c}} \quad$ corrosion rate $(\%)$

d coefficient

e coefficient

$\mathrm{D}_{\mathrm{SE}} \quad$ corrosion depth $(\mathrm{mm})$

$\mathrm{f}_{1} \quad$ pipe-soil potential difference $(-\mathrm{mV})$

$\mathrm{f}_{2} \quad$ water contents $(\%)$

\section{References}

1. Kleiner Y, Rajani B. Forecasting variations and trends in water-main breaks. J. Infrastruct. Syst. 2002;8:122-131. 
2. Rajani B, Makar J. A methodology to estimate remaining service life of grey cast iron water mains. Can. J. Civil Eng. 2000;27: 1259-1272.

3. Lee SH. Prioritizing water pipe replacement and rehabilitation by evaluating failure risk (thesis). Texas A\&M Univ.; 2011.

4. Deb AK, Grablitz FM, Hasit YJ, Snyder JK. Prioritization water main replacement and rehabilitation. AWWARF; 2002.

5. Seo J, Koo M, Kim K, Koo J. A study on the probability of failure model based on the safety factor for risk assessment in a water supply network. Procedia Eng. 2015;119:206-215.

6. Bae CH, Kim JH, Woo HM, Hong SH. Development of residual tensile strength prediction model for metallic water pipes. $J$. Korean Geotech. Soc. 2008;9:17-28.

7. Li CQ, Mahmoodian M. Risk based service life prediction of underground cast iron pipes subjected to corrosion. Reliab. Eng. Syst. Safe. 2013;119:102-108.

8. Wilson D, Filion Y, Moore I. Mechanistic, probabilistic model to estimate the factor of safety of large-diameter cast iron water mains: Sensitivity analysis. Procedia Eng. 2014;89:1390-1396.

9. Shamir U, Howard CDD. An analytic approach to scheduling pipe replacement. J. Am. Water Works Assoc. 1979;71:248-258.

10. Walski TM. Replacement rules for water mains. J. Am. Water Works Assoc. 1987;79:33-37.

11. Herz RK. Ageing process and rehabilitation needs of drinking water distribution networks. J. Water Supply Res. Technol. AQUA 1996;45:221-231.

12. Bruaset S, Saegrov S, Ugarelli R. Performance-based modelling of long-term deterioration to support rehabilitation and investment decisions in drinking water distribution systems. Urban Water J. 2018;15:46-52.

13. Dandy GC, Engelhardt M. Optimal schedule of water pipe replacement using genetic algorithms. J. Water Resour. Plan. Manage. 2001;127:214-223.

14. Dandy GC, Engelhardt MO. Multi-objective trade-offs between cost and reliability in the replacement of water mains. J. Water Resour. Plan. Manage. 2006;132:79-88.

15. Shin H, Joo C, Koo J. Optimal rehabilitation model for water pipeline systems with genetic algorithm. Procedia Eng. 2016; 154:384-390.

16. Kleiner Y, Adams BJ, Rogers JS. Water distribution network renewal planning. J. Comput. Civil Eng. 2001;15:15-26.

17. Park S, Loganathan GV. Optimal pipe replacement analysis with a new pipe break prediction model. J. Korean Soc. Water Wastewater 2002;16:710-716.
18. Kleiner Y, Nafi A, Rajani B. Planning renewal of water mains while considering deterioration, economies of scale and adjacent infrastructure. Water Sci. Technol. Water Supply 2010;10: 897-906.

19. Ramos WL. Benefit/cost analysis procedure for determining water main replacement. In: Proceeding of AWWA Conference Symposium; Denver, Colo; 1985. p. 125-133.

20. Male JW, Walski TM, Slutksy AH. Analyzing water main replacement policies. J. Water Resour. Plan. Manage. 1990;116: 362-374.

21. Gaewski PE, Blaha FJ. Analysis of total cost of large diameter pipe failures. AWWA Research Symposium Distribution Systems: The Next Frontier, Reno, Nev; 2007.

22. Liu Z, Kleiner Y, Rajani B. Condition assessment technologies for water transmission and distribution systems. Cincinnati, OH; US EPA (Environmental Protection Agency); 2012. p. 149.

23. Kim K, Kim M, Choi S, Koo J. A study on economic evaluation for pipeline renewal using contingent valuation method and forecasting pipeline burst. Procedia Eng. 2014;89:870-877.

24. MOLIT (The Korea Ministry of Land, Infrastructure and Transport). Investment evaluation guideline of stabilization project for multi-regional water supply and industrial water supply. 2014. p. Appendix. 3.

25. MOE (The Korea Ministry of Environment). 2015 Statistics of waterworks. 2016.

26. KDI (Korea Development Institute). General guidelines for conducting preliminary feasibility research. 4th ed. 2008. p. 107.

27. KOTI (Korea Transport Institute). Research of national transport demand. 2012. p. 359.

28. K-water. Validation review of optimal renewal period for multi-regional water supply pipelines. Daejeon; K-water; 2015. p. 360.

29. Mays LW. Water supply systems security. McGRAW-HILL; 2003. p. 382.

30. Wagner JM, Shamir U, Marks DH. Water distribution reliability: Analytic methods. J. Water Resour. Plan. Manage. 1988;114: 253-275.

31. Kim K. The optimal renewal planning using dynamic programming in water pipelines (thesis). Seoul: Univ. of Seoul; 2015. p. 193.

32. Balogun II, Sojobi AO, Galkaye E. Public water supply in Logos State, Nigeria: Review of importance and challenges, status and concerns and pragmatic solutions. Cogent Eng. 2017;4: 1329776. 